\title{
Experimental analysis and optimization of mechanical properties of FDM-processed polylactic acid using Taguchi design of experiment
}

\author{
Mohamed Abouelmajd ${ }^{1,{ }^{*}}$, Ahmed Bahlaoui ${ }^{1}$, Ismail Arroub ${ }^{1}$ (D), Maria Zemzami ${ }^{2}$, Nabil Hmina ${ }^{2}$, Manuel Lagache ${ }^{3}$, \\ and Soufiane Belhouideg ${ }^{1}$ (D) \\ ${ }^{1}$ Team of Applied Physics and New Technologies, Department of Physics - Polydisciplinary Faculty, Sultan Moulay Slimane \\ University, Beni Mellal, Morocco \\ ${ }^{2}$ Systems Engineering Laboratory, University Sultan Moulay Slimane, Beni-Mellal, Morocco \\ 3 Polytech Annecy Chambery - Univ. Savoie, SYMME, 74000 Annecy, France
}

Received: 1 March 2021 / Accepted: 26 October 2021

\begin{abstract}
Fused deposition modeling (FDM) is one of the most used additive manufacturing processes in the current time. Predicting the impact of different 3D printing parameters on the quality of printed parts is one of the critical challenges facing researchers. The present paper aims to examine the effect of three FDM process parameters, namely deposition velocity, extrusion temperature, and raster orientation on the bending strength, stiffness, and deflection at break of polylactic acid (PLA) parts using Taguchi design of experiment technique. The results indicate that the temperature has the highest impact on the mechanical properties of PLA specimens followed by the velocity and the orientation. The optimum composition offering the best mechanical behavior was determined. The optimal predicted response was $159.78 \mathrm{~N}, 39.92 \mathrm{~N} / \mathrm{mm}$, and $12.55 \mathrm{~mm}$ for the bending strength, bending stiffness, and deflection at break, respectively. The $R^{2}$ obtained from analysis of variance (ANOVA) showed good agreement between the experimental results and those predicted using a regression model.
\end{abstract}

Keywords: Additive manufacturing / Taguchi method / desirability function / FDM process optimization

\section{Introduction}

Additive manufacturing ( $\mathrm{AM})$, also called 3D printing, refers to a new construction technology of three-dimensional objects by depositing layers one over the others with high precision. AM enables the production of complex tools, prototypes, and models offering the benefit of reasonable cost and short manufacturing time compared to the traditional methods such as machining and molding [1]. The ability to fabricate parts faster, cheaper, and without tooling increases the use of AM in medical sectors, functional prototype development, automobile fields, toolmaking, and many more [2-5]. Currently, AM technology has been developed to manufacture solid parts from a wide variety of materials including ceramics, thermoplastic polymers, and metals [6,7].

Among many AM processes, fused deposition modeling (FDM) is one of the technologies most commonly used by

\footnotetext{
* e-mail: mohamed.abouelmajd@usms.ac.ma
}

consumers in the current time. The FDM process is relatively easier to configure and use compared to the other AM technologies available on the market today. Also, the desktop 3D printers based on FDM process offer the advantage of building parts with short manufacturing duration, low cost, and important flexibility [8]. The small cost and the simplicity of operation make the home users able to prepare and fabricate parts of any idea easily.

The FDM process uses many types of thermoplastic polymers such as polylactic acid (PLA), Nylon, acrylonitrile butadiene styrene (ABS), polycarbonate, and others [9]. The majority of desktop 3D printers based on the FDM technique widely use PLA in the fabrication process. The PLA is a biodegradable polymer made from lactic acid derived from many recycled resources. It has a relatively low melting temperature that is between $190^{\circ} \mathrm{C}$ and $220^{\circ} \mathrm{C}$ $[10,11]$.

Despite the wide number of FDM process benefits, it has a major disadvantage that is the process parameters affect the mechanical performance of printed pieces [12]. Also, the main part of home users has no way to 
Table 1. Factors and Their Selected Levels.

\begin{tabular}{llll}
\hline Level & $\mathrm{V}(\mathrm{mm} / \mathrm{s})$ & $\mathrm{T}\left({ }^{\circ} \mathrm{C}\right)$ & $\mathrm{O}$ (degree) \\
\hline 1 & 30 & 190 & 0 \\
2 & 50 & 200 & 30 \\
3 & 70 & 210 & 60 \\
\hline
\end{tabular}

Table 2. Constant FDM Process Parameters.

\begin{tabular}{lll}
\hline Factor & Value & Unit \\
\hline Infill density & 100 & $\%$ \\
Infill pattern & Rectilinear & - \\
Build orientation & Flat & - \\
Layer thickness & 0.4 & $\mathrm{~mm}$ \\
Air gap & 0 & $\mathrm{~mm}$ \\
Bed temperature & 60 & ${ }^{\circ} \mathrm{C}$ \\
\hline
\end{tabular}

examine the quality of their products. The influence of FDM process settings on the mechanical properties requires specific tests and analysis. Therefore, to make the $3 \mathrm{D}$ printed parts stronger and useful in functional fields, it is necessary to determine the optimal FDM process settings.

Many study were conducted in the last years to optimize the compressive performance [13,14], the tensile properties $[15,16]$ and the flexural behavior of PLA built parts $[17,18]$. Moreover, this study investigates the characteristics of the FDM process parameters and their effects on the mechanical performance of printed parts. Three important mechanical properties namely limit load, bending stiffness, and flexural deflection at break characterize the mechanical response. The study was performed using Taguchi design to examine the effect of FDM process parameters on the response. The analysis of variance (ANOVA) technique was used to determine the percentage of contribution of each parameter in the resulting overall influence. The optimization of process parameters to improve the mechanical properties of printed parts was conducted using the composite desirability function.

\section{Experimental procedure}

Based on previously conducted research studies, three FDM process parameters were taken into consideration. These parameters are defined as follows:

- Deposition velocity $(V)$ : it is the displacement speed of the extruder during the manufacturing period. The speed depends on the type of $3 \mathrm{D}$ printer machine.

- Extrusion temperature $(T)$ : refers to the heating nozzle temperature, which ensures the transformation of thermoplastic polymer into semi-liquid state. It is selected based on the material used and the printed part shape.

- Raster orientation $(O)$ : also called printing angle, it represents the angle formed by the deposited filament and $\mathrm{X}$-axis of the build platform.

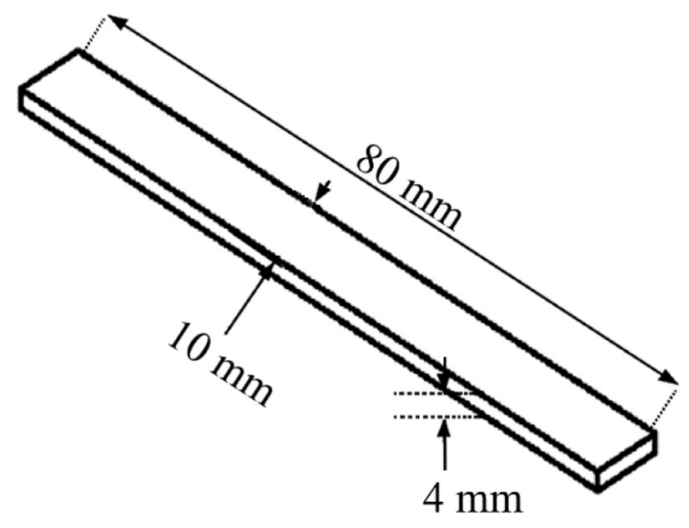

Fig. 1. Dimensions of PLA flexural specimen.

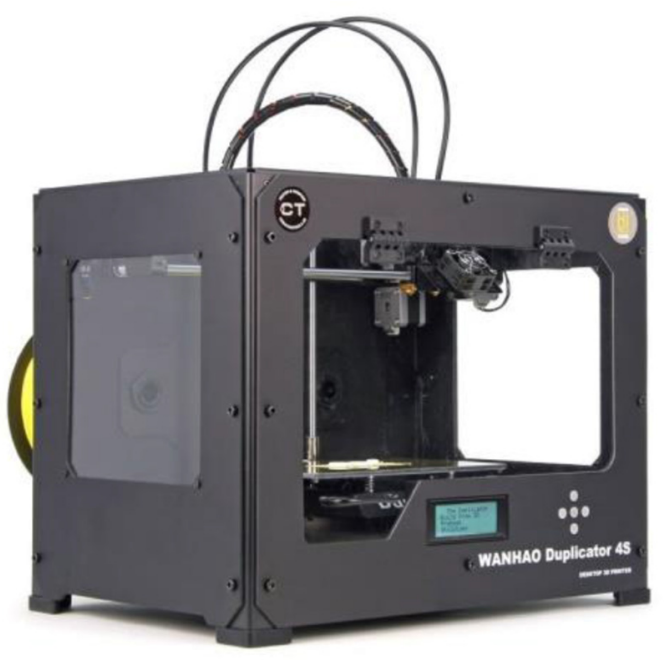

Fig. 2. The $3 \mathrm{D}$ printer machine WANHAO DUPLICATOR $4 \mathrm{~S}$.

Three levels of each parameter were chosen according to the equipment used in this study and the past research works. In order to investigate the effect of FDM process factors on the response of printed parts and extract the response from the fewest number possible of tests, the experiments were conducted according to Taguchi design of experiments method. The FDM process parameters represent the input factors of the design, while the output is characterized by the mechanical response. Table 1 shows the factors considered and their respective levels. The other FDM process parameters such as infill density, infill pattern, build orientation, layer thickness, air gap and bed temperature were kept at their fixed level as mentioned in Table 2.

As shown in Figure 1, three-dimensional models of parallelepiped parts of dimensions $80 \mathrm{~mm}$ long, $10 \mathrm{~mm}$ wide and $4 \mathrm{~mm}$ thick are modeled using a conception aided design (CAD) software. The parts dimensions are chosen according to the ISO 178:2019 standard [19], which describes the experimental procedure followed to determine the bending properties of thermoplastics. The test samples were printed according to the 3D models from the PLA material using WANHAO Duplicator $4 \mathrm{~S}$ printer machine (see Fig. 2). Figure 3 shows part of the samples used in the mechanical test. 
Flexural properties of structures are determined from the results of three-point bending test. This mechanical test is commonly used because of the simplicity and the inexpensiveness of its procedure. As shown in the schema given in Figure 4, a polymer structure is deposited on two supports and a load is applied at the center of the structure. Every PLA specimen was tested under bending load until the fracture to determine its mechanical response. In this study, the three-point bend test was achieved using Instron

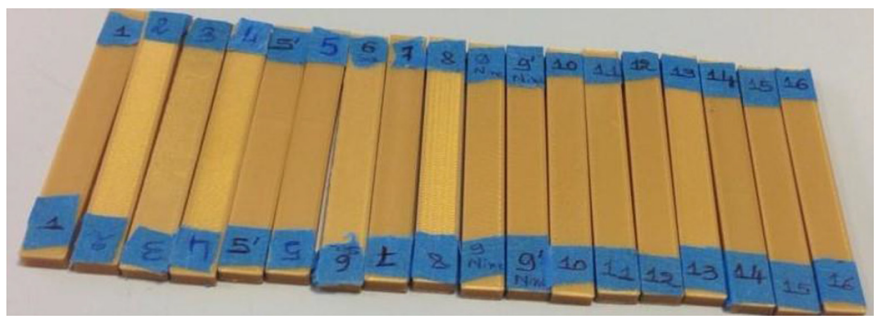

Fig. 3. Part of the samples used in mechanical test.

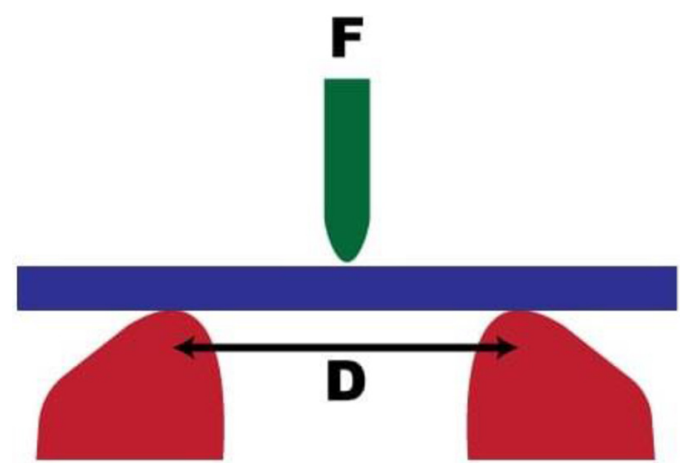

Fig. 4. Schema of three point bending test.
5569 test machine with a crosshead velocity of $2 \mathrm{~mm} / \mathrm{min}$, and a support span $(D)$ of $60 \mathrm{~mm}$. In addition, the test machine has a maximum load cell of $10 \mathrm{KN}$.

The experiments were performed conforming to the orthogonal array of Taguchi Design L9 as shown in Table 3. In order to obtain a reasonable estimate of experimental error, three PLA specimens were tested for each test run and the mean values were taken into account.

\section{Results and discussion}

\subsection{Bending test results}

The testing machine was equipped with an electronic extensometer to determine the applied load in the middle of PLA specimens during the mechanical test. The deflection resulting was measured by a displacement sensor. The data recorded from the three-point bending test machine was collected using a computer system to plot the distribution of the applied load as a function of resulting deflection.

Table 3. Orthogonal Array of Taguchi Design L9.

\begin{tabular}{llll}
\hline Test Run & $\mathrm{V}(\mathrm{mm} / \mathrm{s})$ & $\mathrm{T}\left({ }^{\circ} \mathrm{C}\right)$ & $\mathrm{O}$ (degree) \\
\hline 1 & 30 & 190 & 0 \\
2 & 30 & 200 & 30 \\
3 & 30 & 210 & 60 \\
4 & 50 & 190 & 30 \\
5 & 50 & 200 & 60 \\
6 & 50 & 210 & 0 \\
7 & 70 & 190 & 60 \\
8 & 70 & 200 & 0 \\
9 & 70 & 210 & 30 \\
\hline
\end{tabular}

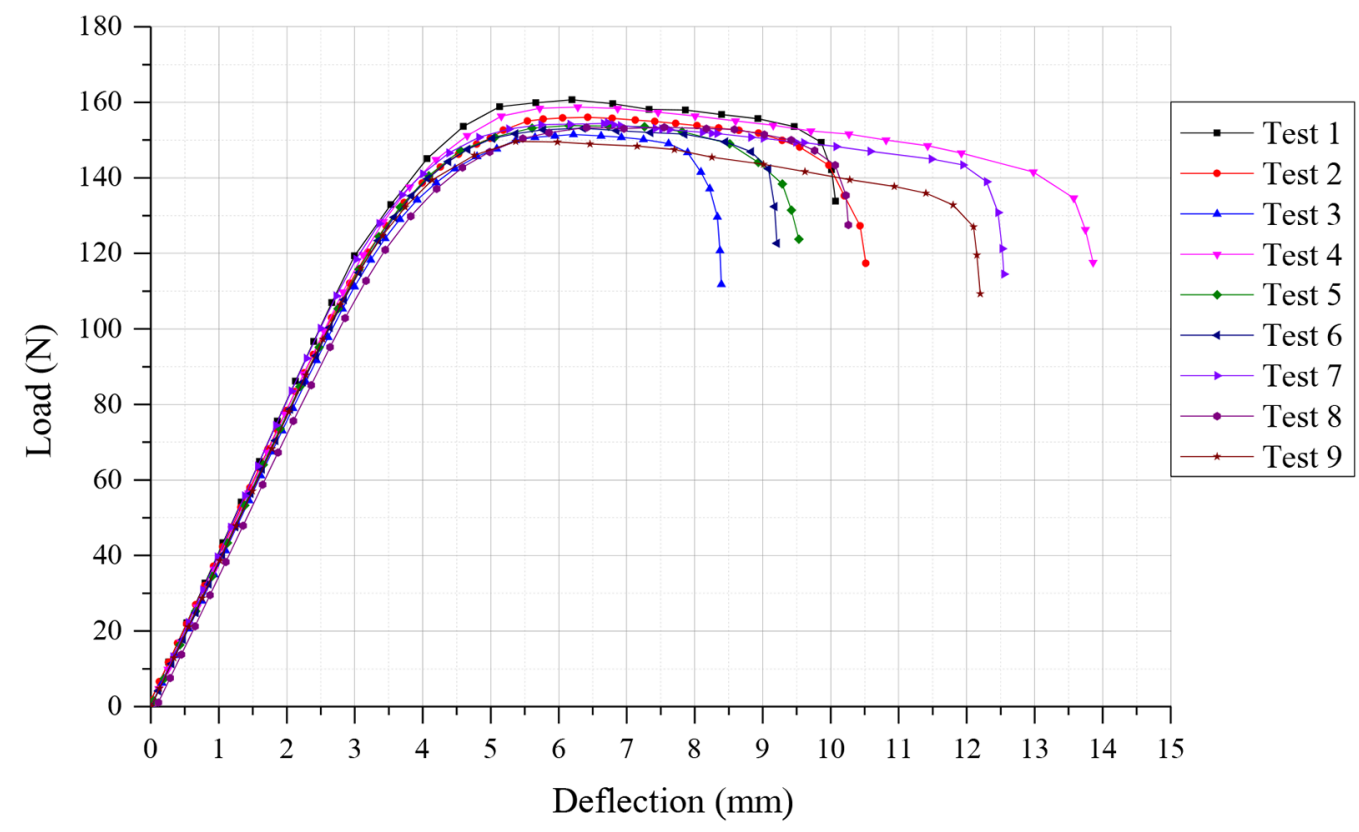

Fig. 5. Load-Deflection curves of PLA structures under bending test. 
The conditions presented in Table 3 were taken into account to fabricate three samples for each test run. Thus, each test run was composed of three samples with the same printing conditions. The samples were tested under bending load, and the mean values between three specimens of the same printing settings were calculated. The Load-Deflection curves of the nine experiments are shown in Figure 5.

Three important mechanical properties have been determined from the Load-Deflection graphs, namely the limit load, bending stiffness, and maximum bending deflection. The mechanical properties are defined as follows:

- Limit Load: characterize the PLA specimen strength; it is the maximal load supported before the fracture.

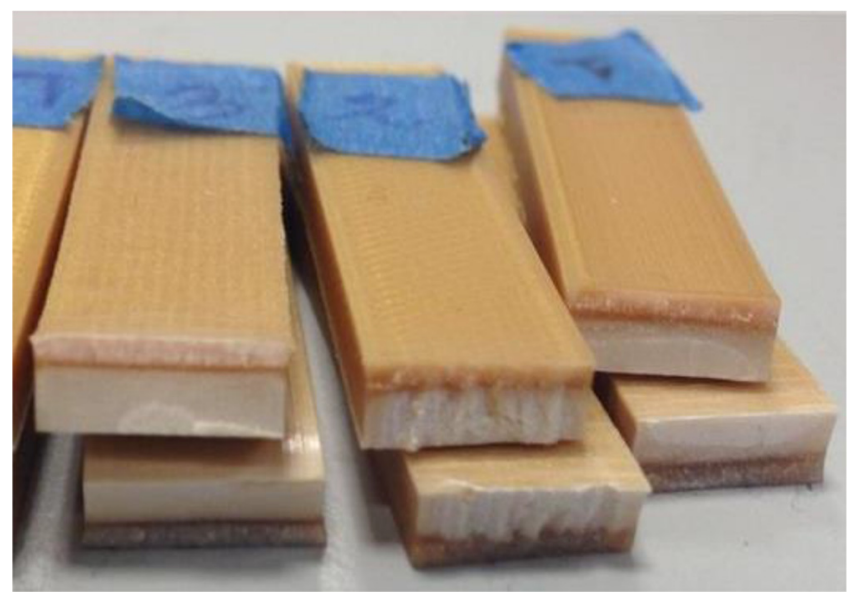

Fig. 6. Fracture surface of PLA samples.
- Bending Stiffness: it is the slope of the Load-Deflection curve in the domain of elastic deformations.

- Deflection at break: refers to the maximum deflection subjected by the specimens.

Taguchi analysis was carried out to investigate the main effect of FDM process factors on the average mechanical properties of PLA parts. For the signal-to-noise S/N ratio, the option larger is better was selected for the response that was to be maximized. In addition, the analysis of variance (ANOVA) was used to identify the statistical significance and the importance of the process parameters' effect on the mechanical behavior of specimens. For a confidence level of $95 \%$, if the $p$-value is less than 0.05 , the effect of the corresponding factor is statistically significant.

The fracture surfaces of the specimens used in the bending test are illustrated in Figure 6. The surface of each sample is composed of two zones, a white zone formed by a section solicited in tension and a brown part that represents the compressed face. The observation of the fracture facets shows the ductile behavior of the different test pieces. The rapid rupture is produced after progressive damage of the specimens presented by the propagation of cracks, as indicated by the combination of rough and smooth fracture surfaces. The upper part of the specimen during the test was rigorous in comparison with the lower part which is relatively smooth.

\subsection{The limit load}

A graphical comparison of limit load at the different experiments is depicted in Figure 7. In this figure, the average limit load of PLA specimens fabricated with the same settings was determined for each test run. The main

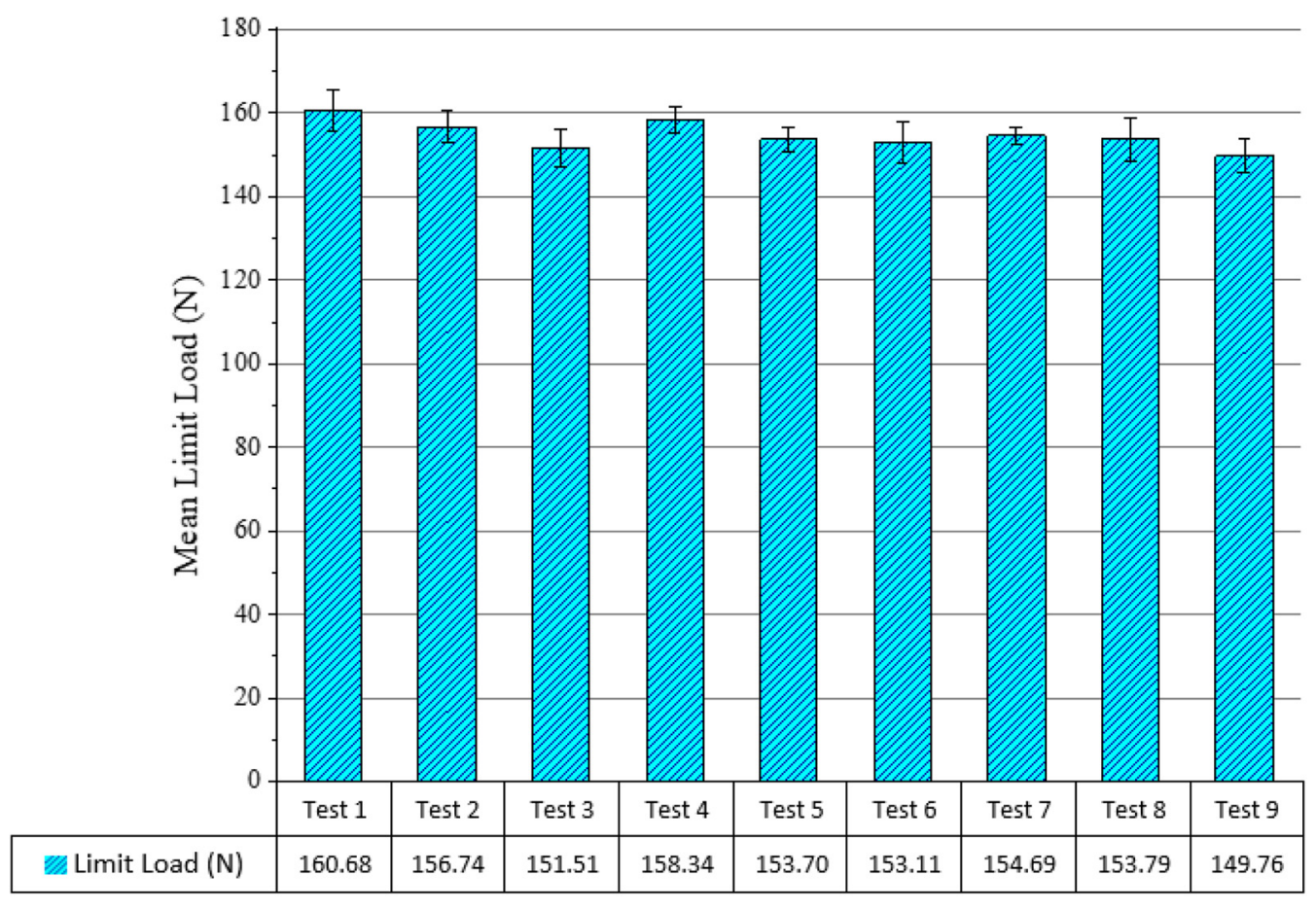

Fig. 7. Limit bending load of PLA specimens. 
Table 4. ANOVA Analysis For Limit Bending Load.

\begin{tabular}{|c|c|c|c|c|c|c|}
\hline Source & DoF & Sum of Squares & Mean of Squares & F value & $\mathrm{P}$ value & $\mathrm{PoC}$ \\
\hline Velocity & 2 & 19.9010 & 9.9505 & 117.84 & 0.008 & $21 \%$ \\
\hline Temperature & 2 & 62.3995 & 31.1997 & 369.47 & 0.003 & $67 \%$ \\
\hline Orientation & 2 & 9.8447 & 4.9224 & 58.29 & 0.017 & $11 \%$ \\
\hline Residual Error & 2 & 0.1689 & 0.0844 & & & \\
\hline Total & 8 & 92.3141 & & & & \\
\hline R squared & \multicolumn{3}{|c|}{ R squared (adjusted) } & \multirow{2}{*}{\multicolumn{3}{|c|}{ R squared (predicted) }} \\
\hline $99.82 \%$ & & 99. & & & & \\
\hline
\end{tabular}

DoF: Degree of Freedom ; PoC: Percentage of Contribution.

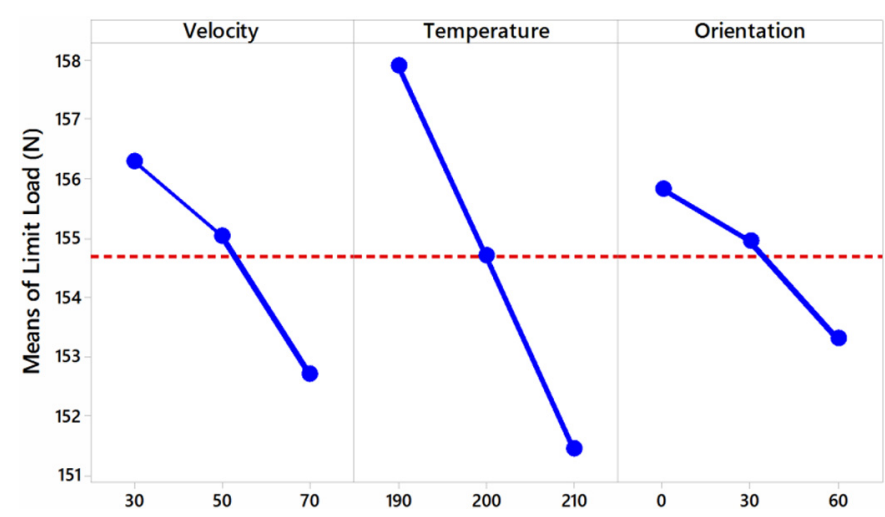

Fig. 8. Main effect for means of limit load plot.

effect plot for the means limit load based on Taguchi analysis is shown in Figure 8. The ANOVA results for limit bending load are listed in Table 4 .

The comparison of the minimum and maximum average values of limit load showed deviation between PLA parts manufactured with different printing settings in the range of $[160.68 ; 149.76] \mathrm{N}$. The limit load values obtained were in accordance with those found by Kumar et al. and Aloyaydi et al. [20,21]. The maximal value was obtained during the first test, while specimens used in Test 9 have the lowest average limit load. From the main effects of process parameters shown in Figure 8, it can be seen that the limit load decreases with decreasing deposition velocity, extrusion temperature, and raster orientation. Based on Taguchi analysis, the optimized process parameters for achieving maximal limit load are $30 \mathrm{~mm} / \mathrm{s}$ deposition velocity, $190^{\circ} \mathrm{C}$ extrusion temperature, and 0 degree raster orientation.

The ANOVA results show that the three factors considered have a statistically significant effect on the limit load $(p<0.05)$. In addition, it shows that the extrusion temperature has the highest impact on the limit load with a Percentage of Contribution (PoC) of $67 \%$, followed by deposition velocity influence of $21 \%$, while the lowest effect is characterized by the raster orientation with $11 \%$. The R-squared and adjusted R-squared values of ANOVA for the limit load, $99.82 \%$, and $99.27 \%$ respectively, show a good fitting of the model to the experimental results.

\subsection{The bending stiffness}

The results of bending stiffness of the PLA products are presented in Figure 9. The average bending stiffness obtained ranges from $37.85 \mathrm{~N} / \mathrm{mm}$ to $40.19 \mathrm{~N} / \mathrm{mm}$. These results were in line with those reported in the literature for the PLA material manufactured using fused deposition modeling technology and under different printing conditions [22,23]. The maximum bending stiffness was reached at Test 1 and the minimum stiffness presents in specimens used in Test 8 . It observed from the main effect plot for means bending stiffness (Fig. 10) that the lowest deposition velocity and extrusion temperature, $30 \mathrm{~mm} / \mathrm{s}$ and $190^{\circ} \mathrm{C}$ respectively, and the high level of raster orientation (60 degree) were the combination of the optimal levels to improve the bending stiffness of PLA parts.

The ANOVA for the bending stiffness was calculated and summarized in Table 5. The p-values obtained from ANOVA analysis indicate that the impact of the three process parameters considered was statistically significant with a $p$-value less than 0.05 . Moreover, the extrusion temperature shows the highest influence on bending stiffness with a contribution ratio of $72 \%$, followed by raster orientation and deposition velocity at reduced $\mathrm{PoC}$ of $14 \%$ and $13 \%$, respectively. The high values of $R$-squared (greater than 99\%) show that the data fits adequately.

\subsection{The maximum deflection}

The comparison of the average deflection at break of three repeated experiments during each test is depicted in Figure 11. It is clear from this figure that the mean deflection at break was raging between $8.39 \mathrm{~mm}$ obtained at Test number 3 and $13.85 \mathrm{~mm}$ achieved during the experiments of Test 4 . These results were in agreement with the deflection at break reported in previous studies $[24,25]$. From the main effect plot for deflection at break shown in Figure 12, it is observed that the bending 
Table 5. ANOVA Analysis For Bending Stiffness.

\begin{tabular}{|c|c|c|c|c|c|c|}
\hline Source & DoF & Sum of Squares & Mean of Squares & F value & $\mathrm{P}$ value & $\mathrm{PoC}$ \\
\hline Velocity & 2 & 0.82169 & 0.41085 & 109.48 & 0.009 & $13 \%$ \\
\hline Temperature & 2 & 4.11429 & 2.05714 & 548.17 & 0.002 & $72 \%$ \\
\hline Orientation & 2 & 0.79882 & 0.39941 & 106.43 & 0.009 & $14 \%$ \\
\hline Residual Error & 2 & 0.00751 & 0.00375 & & & \\
\hline Total & 8 & 5.74231 & & & & \\
\hline R squared & \multirow{2}{*}{\multicolumn{3}{|c|}{$\begin{array}{l}\text { R squared (adjusted) } \\
99.48 \%\end{array}$}} & \multirow{2}{*}{\multicolumn{2}{|c|}{$\begin{array}{l}\text { R squared (predicted) } \\
97.35 \%\end{array}$}} & \\
\hline $99.87 \%$ & & & & & & \\
\hline
\end{tabular}

DoF: Degree of Freedom ; PoC: Percentage of Contribution.

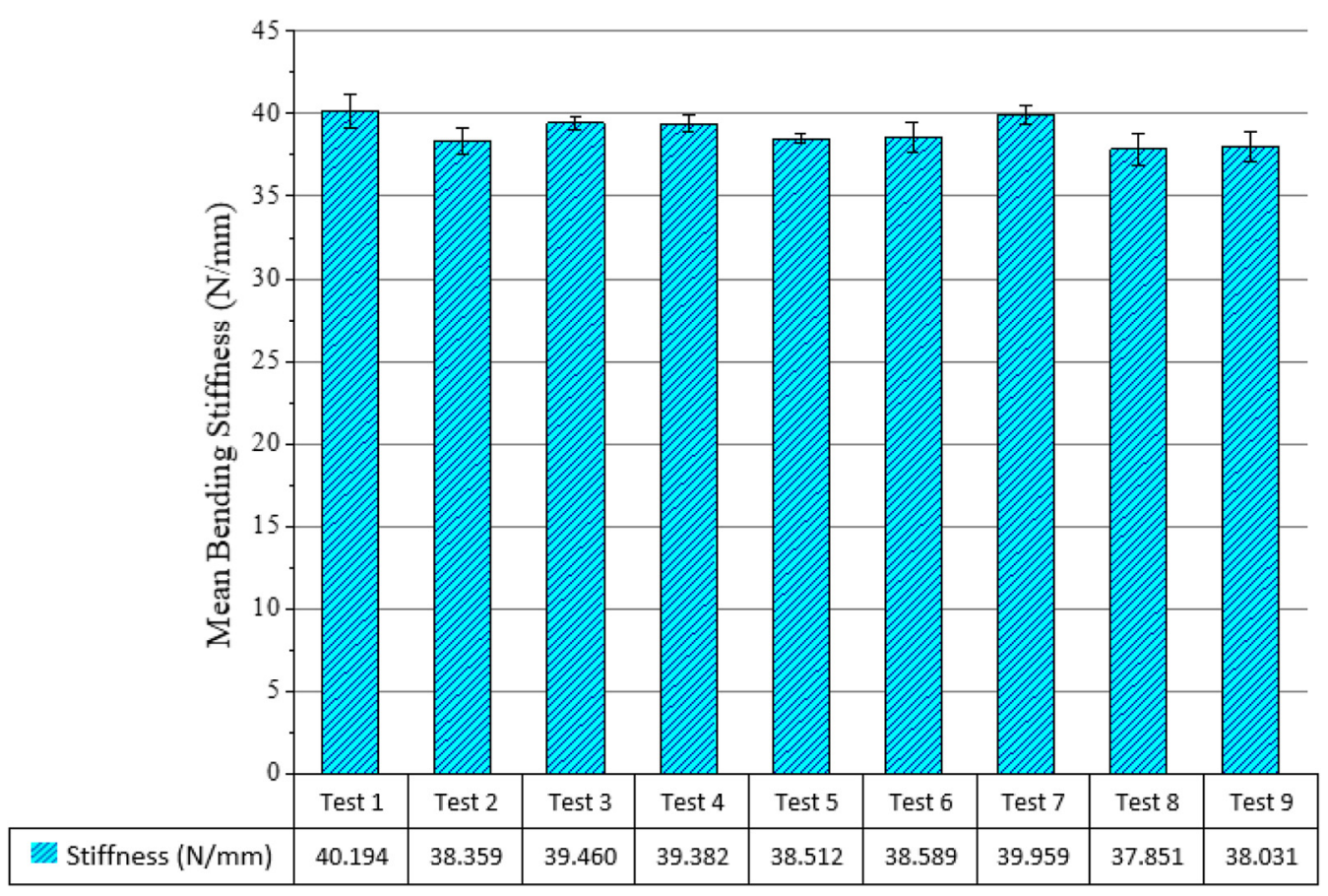

Fig. 9. Bending stiffness of PLA specimens.

deflection at break will be maximal for deposition velocity of $70 \mathrm{~mm} / \mathrm{s}$, extrusion temperature of $190^{\circ} \mathrm{C}$, and raster orientation of 0 degree.

The ANOVA results presented in Table 6, show that the factors considered have a $p$-value less than 0.05 , which implies the significance of their effect on the maximum bending deflection. Also, it shows that the raster orientation and the extrusion temperature have an important impact on the maximum bending deflection with a contribution ratio of $38 \%$ and $37 \%$ respectively, followed by the influence of deposition velocity on bending deflection with $24 \%$ of contribution in the total deviations produced. The $R$-squared values obtained from the ANOVA table, $99.66 \%$ of $R$-squared, $98.65 \%$ of adjusted $R$-squared indicate that the regression ANOVA model excellently fits the experimental data.

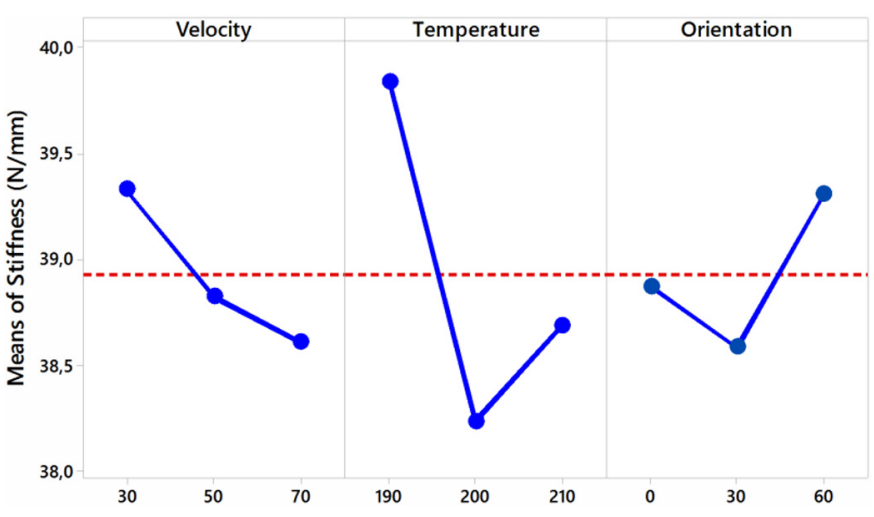

Fig. 10. Main effect for means of bending stiffness plot. 
Table 6. ANOVA Analysis For Deflection at Break.

\begin{tabular}{|c|c|c|c|c|c|c|}
\hline Source & DoF & Sum of Squares & Mean of Squares & $\mathrm{F}$ value & $\mathrm{P}$ value & $\mathrm{PoC}$ \\
\hline Velocity & 2 & 6.2476 & 3.12379 & 73.04 & 0.014 & $24 \%$ \\
\hline Temperature & 2 & 9.2907 & 4.64537 & 108.62 & 0.009 & $37 \%$ \\
\hline Orientation & 2 & 9.6788 & 4.83938 & 113.15 & 0.009 & $38 \%$ \\
\hline Residual Error & 2 & 0.0855 & 0.04277 & & & \\
\hline Total & 8 & 25.3026 & & & & \\
\hline R squared & \multirow{2}{*}{\multicolumn{3}{|c|}{$\begin{array}{l}\text { R squared (adjusted) } \\
98.65 \%\end{array}$}} & \multirow{2}{*}{\multicolumn{2}{|c|}{$\begin{array}{l}\text { R squared (predicted) } \\
93.15 \%\end{array}$}} & \\
\hline $99.66 \%$ & & & & & & \\
\hline
\end{tabular}

DoF: Degree of Freedom ; PoC: Percentage of Contribution.

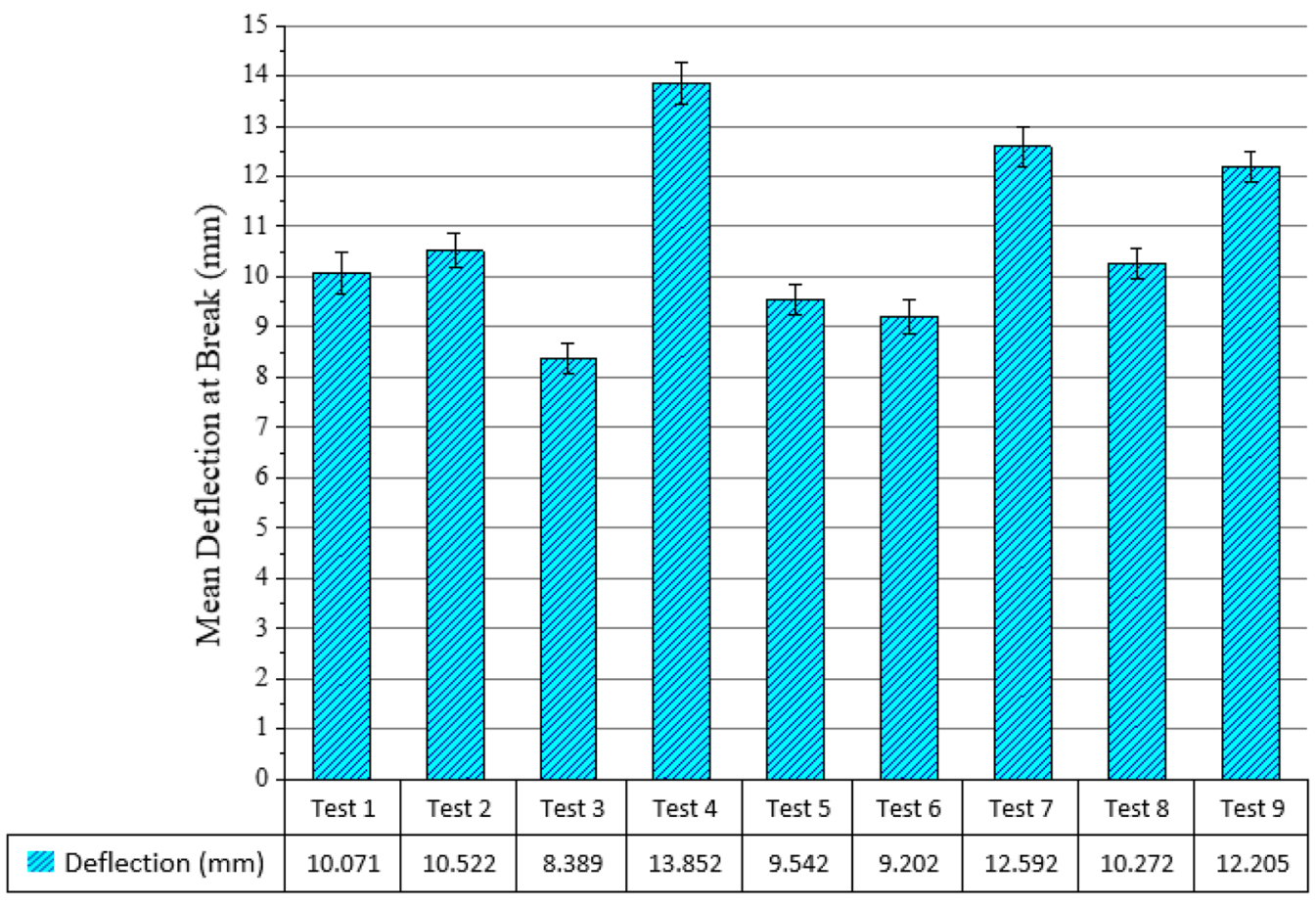

Fig. 11. Deflection at break of PLA specimens.

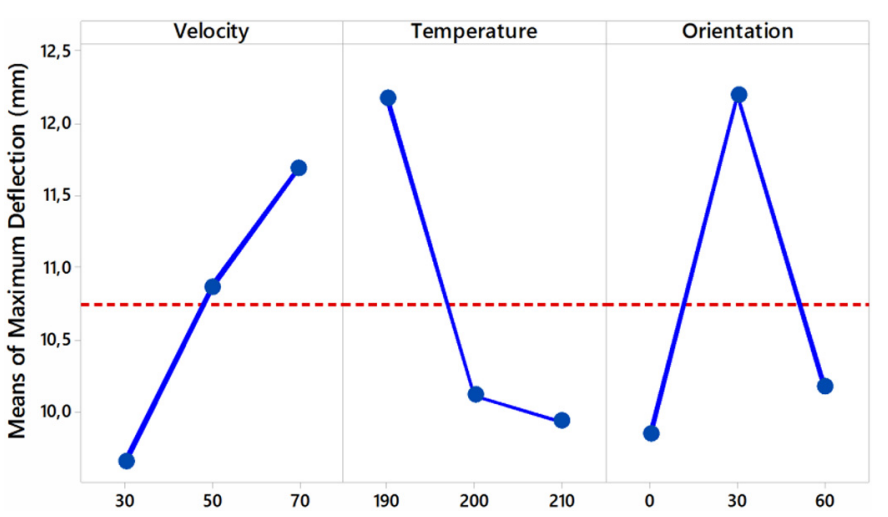

Fig. 12. Main effect for means of maximum deflection plot.

\subsection{Composite optimization}

Taguchi analysis used to optimize the FDM process parameters remains a limited method. Each optimal combination obtained through this method will only improve just the corresponding mechanical property. For this reason, the composite desirability function was applied to perform multi-objective optimization. The composite desirability function is a suitable method to determine the optimal combination that maximizes all mechanical responses simultaneously together.

The approach based on the desirability function involves converting estimated response models (mechanical property) into individual desirability functions $(d)$, which are then collected into a composite desirability function $(D)$. The variation range of individual desirability $(d)$ was from 0 to 1 . The optimization results represent 
a completely undesirable value for a zero desirability $(d=0)$, while $d=1$ represents a completely desirable response value. Based on the response specifications, three options of individual desirability functions are available:

- Smaller is better: for a purpose to minimize the response.

- Larger is better: for an objective to maximize the response.

- Target: a specific value of response was the best.

In this paper, we intend to maximize the three mechanical responses (limit load, bending stiffness, and bending deflection at break). Thus, the second option of the individual desirability function (Larger is better) was chosen. To maximize the mechanical properties, the individual desirability $(d)$ was calculated using equation (1).

$$
d=\left\{\begin{array}{cl}
0 & ; \text { if } y \leq y_{\text {low }} \\
\left(\frac{y-y_{\text {low }}}{y_{\text {high }}-y_{\text {low }}}\right)^{w} ; & \text { if } \quad y_{\text {low }}<y<y_{\text {high }} \\
1 & ; \text { if } y \geq y_{\text {high }}
\end{array}\right.
$$

where $y$ is the found value of the mechanical response, $y_{\text {low }}$ and $y_{\text {high }}$ are the minimum and maximum response values respectively, and $w$ is the weight variable. Since the limit load, bending stiffness, and bending deflection at break are equally important, the value of weight variable $w$ was taken equal to 1 . The composite desirability function $(D)$, as the geometric mean of the individual desirability functions $\left(d_{\mathrm{i}}\right)$, was calculated using equation (2).

$$
D=\left(\prod_{i=1}^{n} d_{i}\right)^{\frac{1}{n}}
$$

here, $n$ represents the number of responses.

In this study, the desirability function combined three mechanical responses into one composite desirability function $(D)$, which is given by equation (3).

$$
\begin{aligned}
D= & {[d(\text { Limit load }) \times d(\text { Bending stiffness })} \\
& \times d(\text { Deflection at break })]^{1 / 3}
\end{aligned}
$$

The composite optimization for FDM parameters and the predicted mechanical properties are given in Figure 13. The dashed lines, blue, and horizontal represent the optimum levels that will maximize each mechanical response individually. An accordance was observed between the optimization obtained through the individual desirability function and the Taguchi analysis. The same optimal combinations were determined by the two approaches. The solid, red, and vertical lines indicate the optimum levels for the limit load, bending stiffness, and bending deflection at break simultaneously.

As shown in Figure 13, the optimum combination that will improve the three mechanical properties considered simultaneously was $\left[30 \mathrm{~mm} / \mathrm{s}, 190^{\circ} \mathrm{C}, 30^{\circ}\right]$ for deposition velocity, extrusion temperature, and raster orientation respectively. The optimal predicted response of the limit

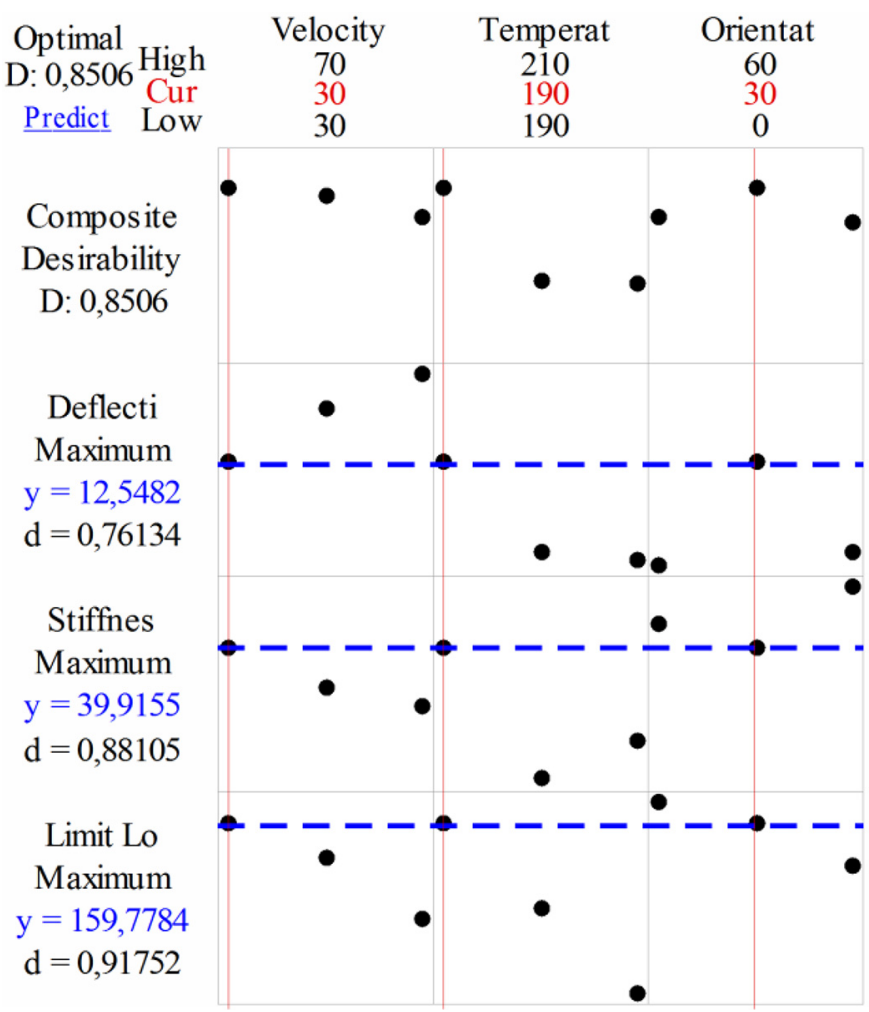

Fig. 13. Composite optimization plot.

load, bending stiffness, and deflection at break was $159.78 \mathrm{~N}, 39.92 \mathrm{~N} / \mathrm{mm}$, and $12.55 \mathrm{~mm}$, respectively. The optimization was performed with excellent composite desirability that is relatively close to $1(D=0.85)$.

\section{Conclusion}

In this experimental investigation, efforts are made to investigate the influence of three FDM process parameters such as deposition velocity, extrusion temperature, and raster orientation on three important mechanical properties, namely limit load, bending stiffness, and bending deflection at break using Taguchi design of experiment method and analysis of variance technique. The deposition velocity is taken equal to $30 \mathrm{~mm} / \mathrm{s}, 50 \mathrm{~mm} / \mathrm{s}$, and $70 \mathrm{~mm} / \mathrm{s}$. Three values of extrusion temperature were studied such as $190{ }^{\circ} \mathrm{C}, 200^{\circ} \mathrm{C}$, and $210^{\circ} \mathrm{C}$. Three levels of raster orientation were considered which are $0^{\circ}, 30^{\circ}$, and $60^{\circ}$. The mechanical proprieties of PLA samples were determined from the experimental results of three-point bending test. The Analysis of Variance was performed to assess the percentage of contribution of printing parameters in the effect on the mechanical behavior of printed parts. The ANOVA results show that the data fits adequately.

In addition, the ANOVA results show that the contribution ratio was related to the considered mechanical property. Generally, the extrusion temperature has the most important contribution ratio in the influence on the mechanical performance of printed structures. The opti- 
mization results indicate that a velocity of $30 \mathrm{~mm} / \mathrm{s}$, temperature of $190^{\circ} \mathrm{C}$, and orientation of $0^{\circ}$ gives the maximum bending strength. On other hand, the highest bending stiffness was found at $30 \mathrm{~mm} / \mathrm{s}$ of velocity, $190^{\circ} \mathrm{C}$ of temperature, and $60^{\circ}$ of orientation. The combination formed by a velocity of $70 \mathrm{~mm} / \mathrm{s}$, temperature of $190^{\circ} \mathrm{C}$, and orientation of $30^{\circ}$ shows the possibility of producing parts with a high deflection at break. It is observed that the optimal printing parameters are determined according to the mechanical property. The optimal process parameters combination for the limit load was not necessarily the combination of printing settings that allows us to improve another mechanical property. Therefore, the multi-objective optimization was performed using the desirability function. The optimum printing parameters combination for improving the mechanical properties of PLA parts simultaneously was found to be $\left[30 \mathrm{~mm} / \mathrm{s}, 190^{\circ} \mathrm{C}, 30^{\circ}\right]$.

\section{References}

1. M. Chaudhari, B.F. Jogi, R. Pawade, Comparative study of part characteristics built using additive manufacturing (FDM), Proc. Manufactur. 20, 73-78 (2018)

2. M.K. Thompson, G. Moroni, T. Vaneker, G. Fadel, R.I. Campbell, I. Gibson et al., Design for additive manufacturing: trends, opportunities, considerations, and constraints, CIRP Ann. 65, 737-60 (2016)

3. J.S. Mohammed, Applications of 3D printing technologies in oceanography, Methods Oceanogr. 17, 97-117 (2016)

4. Z. Liu, Y. Wang, B. Wu, C. Cui, Y. Guo, C. Yan, A critical review of fused deposition modeling $3 \mathrm{D}$ printing technology in manufacturing polylactic acid parts, Int. J. Adv. Manufactur. Technol. 102, 2877-89 (2019)

5. M. Abouelmajd, A. Bahlaoui, I. Arroub, M. Lagache, S. Belhouideg, Mechanical characterization of PLA used in manufacturing of 3D printed medical equipment for COVID19 pandemic, 2020 IEEE 2nd International Conference on Electronics, Control, Optimization and Computer Science (ICECOCS), IEEE (2020), pp. 1-5

6. I. Gibson, D. Rosen, B. Stucker, M. Khorasani, Materials for Additive Manufacturing. Additive Manufacturing Technologies (Springer; 2021), pp. 379-428

7. J. Gardan, Smart materials in additive manufacturing: state of the art and trends, Virtual Phys. Prototyp. 14, 1-18 (2019)

8. V.E. Kuznetsov, A.N. Solonin, O.D. Urzhumtsev, R. Schilling, A.G. Tavitov, Strength of PLA components fabricated with fused deposition technology using a desktop $3 \mathrm{D}$ printer as a function of geometrical parameters of the process, Polymers 10, 313 (2018)

9. D. Bourell, J.P. Kruth, M. Leu, G. Levy, D. Rosen, A.M. Beese et al., Materials for additive manufacturing, CIRP Ann. 66, 659-81 (2017)

10. M, Van den Eynde, P. Van Puyvelde, 3D Printing of Poly (lactic acid). Industrial Applications of Poly (lactic acid) (2017), pp. 139-58
11. X. Zhou, S.-J. Hsieh, Y. Sun, Experimental and numerical investigation of the thermal behaviour of polylactic acid during the fused deposition process, Virtual Phys. Prototyp. 12, 221-33 (2017)

12. J.R.C. Dizon, A.H. Espera Jr, Q. Chen, R.C. Advincula, Mechanical characterization of 3D-printed polymers, Addit. Manufactur. 20, 44-67 (2018)

13. S. Brischetto, R. Torre, Tensile and compressive behavior in the experimental tests for PLA specimens produced via fused deposition modelling technique, J. Compos. Sci. 4, 140 (2020)

14. H.K. Dave, S.R. Rajpurohit, N.H. Patadiya, S.J. Dave, K.S. Sharma, S.S. Thambad et al., Compressive strength of PLA based scaffolds: effect of layer height, infill density and print speed, Int. J. Mod. Manuf. Technol. 11, 21-27 (2019)

15. Y. Zhao, Y. Chen, Y. Zhou, Novel mechanical models of tensile strength and elastic property of FDM AM PLA materials: experimental and theoretical analyses, Mater. Des. 181, 108089 (2019)

16. T. Yao, Z. Deng, K. Zhang, S. Li, A method to predict the ultimate tensile strength of $3 \mathrm{D}$ printing polylactic acid (PLA) materials with different printing orientations, Compos. B 163, 393-402 (2019)

17. C. Abeykoon, P. Sri-Amphorn, A. Fernando, Optimization of fused deposition modeling parameters for improved PLA and ABS 3D printed structures, Int. J. Lightweight Mater. Manufact. 3, 284-97 (2020)

18. S.R. Rajpurohit, H.K. Dave, Flexural strength of fused filament fabricated (FFF) PLA parts on an open-source 3D printer, Adv. Manufactur. 6, 430-41 (2018)

19. I. Standard, ISO B. Plastics-Determination of flexural properties, ISO Geneva, Switzerland (2019)

20. S. Kumar, R. Singh, M. Singh, T. Singh, A. Batish, Multi material $3 \mathrm{D}$ printing of PLA-PA6 $/ \mathrm{TiO}_{2}$ polymeric matrix: Flexural, wear and morphological properties, J. Thermoplast. Compos. Mater. 0892705720953193 (2020)

21. B.A. Aloyaydi, S. Sivasankaran, H.R. Ammar, Influence of infill density on microstructure and flexural behavior of $3 \mathrm{D}$ printed PLA thermoplastic parts processed by fusion deposition modeling, AIMS Mater. Sci. 6, 1033-48 (2019)

22. J. Chacón, M.A. Caminero, E. García-Plaza, P.J. Núnez, Additive manufacturing of PLA structures using fused deposition modelling: effect of process parameters on mechanical properties and their optimal selection, Mater. Des. 124, 143-57 (2017)

23. J. Porter, T. Cain, S. Fox, P. Harvey, Influence of infill properties on flexural rigidity of 3D-printed structural members, Virtual Phys. Prototyp. 14, 148-59 (2019)

24. Z. Liu, Q. Lei, S. Xing, Mechanical characteristics of wood, ceramic, metal and carbon fiber-based PLA composites fabricated by FDM, J. Mater. Res. Technol. 8, 3741-51 (2019)

25. S.Z. Gebrehiwot, L.E. Leal, J. Eickhoff, L. Rechenberg, The influence of stiffener geometry on flexural properties of 3D printed polylactic acid (PLA) beams, Progr. Additive Manufactur. 6, 71-81 (2021)

Cite this article as: Mohamed Abouelmajd, Ahmed Bahlaoui, Ismail Arroub, Maria Zemzami, Nabil Hmina, Manuel Lagache, Soufiane Belhouideg, Experimental analysis and optimization of mechanical properties of FDM-processed polylactic acid using Taguchi design of experiment, Int. J. Simul. Multidisci. Des. Optim. 12, 30 (2021) 